\title{
Spectrum of medical and surgical patients in ophthalmology department of a Government medical college in Bankura district of West Bengal - A retrospective review
}

\author{
Ratandeep Kumar Agrawalla ${ }^{1}$, Anup Mondal ${ }^{2 *}$ \\ ${ }^{1}$ Senior Resident, ${ }^{2}$ Assistant Professor, Dept. of Ophthalmology, Bankura Sammilani Medical College and Hospital, Bankura, West Bengal, \\ India \\ *Corresponding Author: Anup Mondal \\ Email: dr.anup.mondal@gmail.com
}

\begin{abstract}
Purpose: the aim of the study was to determine the pattern of ocular morbidity and to assess various types of surgeries performed for various ophthalmic condition in a comprehensive eye set up in rural population of southern part of west Bengal.

Materials and Methods: A retrospective study involving all the cases presenting to eye department of BSMCH, Bankura from $1^{\text {st }}$ July 2018 to $30^{\text {th }}$ June 2019. Patients were evaluated and treated by medical management or surgery as indicated.

Results: A total of 108628 patients were evaluated and treated. Refractive error is the most common condition followed by cataract $(15.68 \%)$ however only $5.31 \%$ patients were operated because of low turn over due to lack of awareness about ocular health. Conjunctivitis is the $3^{\text {rd }}$ most common manifestation managed conservatively. In retina clinic diabetic retinopathy and vein occlusion are the leading causes of ocular morbidity.

Conclusion: The pattern of eye diseases observed rural population of southern part of west Bengal is similar to other studies conducted in other parts of developing world which helps in better understanding, planning, management and prevention of blindness and ocular morbidity.
\end{abstract}

Keywords: Ocular morbidity, Blindness, Low vision.

\section{Introduction}

Sense of sight is supreme among all the sense provided by god to human beings. World wide approximately about 285 million of people are visually impaired, $90 \%$ of whom live in developing countries like India. $80 \%$ of blindness and $85 \%$ of moderate or severe visual impairment is avoidable by prevention, treatment or cure. ${ }^{1}$ As per WHO, in India by the year 2020 around $1.37 \%$ population, i.e around 18 million people will have blindness or low vision. ${ }^{2}$

Over the last few years, the health standard of people of rural areas of India has improved but visual health has been lagging and often neglected by both people themselves and by the government. Undiagnosed ocular morbidity hampers the quality of life and economic productivity significantly. Although vision 2020 programme has reduced avoidable blindness nationally but its effect are not felt in rural areas due to lack of infrastructure and lack of public awareness. Moreover the pattern of ocular morbidity is changing rapidly in last few decades. Very few studies have been done to evaluate the prevalence and distribution of ocular morbidities in rural population in West Bengal. Moreover functioning of a tertiary hospital may be reviewed from the retrospective evaluation of both OPD, IPD and number of different surgeries or procedures performed so that a proper data may be obtained about actual causes of ocular condition and thus proper planning may be done for reducing the burden in coming years.

\section{Aims and Objectives}

1. To determine the pattern of ocular morbidity in rural population of southern part of West Bengal.

2. To evaluate the treatment and intervention received by the population.
3. To assess various types of surgeries performed for various ophthalmic condition in this comprehensive eye set up.

\section{Description of ophthalmology department}

Bankura is one of the most underdeveloped area in West Bengal. A government medical college in this area serves around 100 square KM area including people from near by districts and states. The department of ophthalmology in this medical college has 1 professor, 2 associate professors, 2 assistant professors and 2 senior residents, posted by government of West Bengal. All the faculty members are trained in cataract surgery, 1 faculty member is pediatric ophthalmologist, 1 is trained in medical retina, 1 is trained in oculoplastic, 1 is trained for glaucoma.

Instrumentation list - in the department we have 2 slit lamps, 1 non contact tonometer, 1 autorefractometer, 2 a scan machines, 1 manual keratometer, 1 YAG LASER along with slit lamp, 1 oct machine, 2 operating microscopes, 1 OCT machine, I green LASER machine, 1 indirect ophthalmoscope, 3 autoclave machines and 2 direct ophthalmoscopes, 1 - 4 mirror gonioscope, 1 - 90 D lens, 1 $78 \mathrm{D}$ lens, 1 humphrey visual field analyser are available.

The opd working hours are from 9 am to $2 \mathrm{pm}$ on working days. In the indoor there are 30 beds (15 each for males and females).

\section{Daily routine}

The day starts with a morning round by the faculty members and tehn the patients are evaluated post operatively, preoperative patients are evaluated by the operating surgeon for the final time and patients admitted for conservative management are assessed. 
All the faculty members go to the seminar room for discussion on a given topic for the day after presentation by any one of them, on Tuesday Thursday and Saturday of every week.

On Monday school health programme is organized in which 1 faculty member along with optometrists goes to different schools of the districts.

On Wednesday handicap and disability board functions in which 1 faculty member is appointed to evaluate and categories the patients with ocular morbidities. A record of causes of ocular morbidity like cornel opacity, retinitis pigmentosa, optic atrophy, amblyopia, microphthalmous etc is maintained.

On Friday performance review meeting is held.

All the faculties are posted in 2 units. Unit 1 have admission day on Monday Wednesday and Friday and unit 2 have admission day on Tuesday Thursday and Saturday. The patients which are being admitted on a given day are planned for operation on the next day and are evaluated postoperatively after 24 hours.

\section{Opd clinics}

Paediatrics and neuroophthalmology clinic is held on Monday, medical retina and ROP clinic on Wednesday, Oculoplasty clinic on Friday. Everyday comprehensive ophthalmology evaluation is done.

Operation theatre for planned and routine surgery is from 9.00 am onwards on working days and emergency operation are done through out the day everyday.

Surgeries performedin planned / routine OT

1. Small incision cataract surgery,

2. phacoemulsification,

3. Intraocular lens exchange and iol implantation for iol opacification

4. Secondary iol implantation with anterior vitrectomy for aphakia correction

5. Phacoemulsification with anterior vitrectomy for congenital cataract,

6. Trabeculectomy,

7. Pterygium excision with conjunctival autografting,
8. Incision and curettege of chalazion,

9. Dacryocystectomy,

10. Dacryocystorhinostomy,

11. Ectropion and entropion correction

12. Resection and recession of recti for squint surgery.

13. Intravitreal injections of anti VEGF

14. Intravitreal injections of antibiotics and steroids

15. Enucleation and evisceration

16. Ptosis correction

17. Lid mass with lid recostruction

\section{Materials and Methods}

This is a retrospective analytical study conducted from $1^{\text {st }}$ July 2018 to $30^{\text {th }}$ June 2019 in department of ophthalmology, BSMCH, Bankura. All the patients attended the ophthalmology OPD were included in this study irrespective of age. Patients were first attended by optometrists and visual assessment by age appropiate method was done. The patient was next attended by ophthalmologist and tested for ocular movements and pupil examination was done with torch light, anterior segment was examined by slit lamp. Intraocular pressure was evaluated by non-contact tonometer or applanation tonometer. Dilated fundus examination was done using 90 $\mathrm{D}$ and $20 \mathrm{D}$ lenses.

After assessment, the patients were prescribed glasses, medications or surgery / intervention as required. Patients needing further investigations like OCT, USG B SCAN, VEP, Visual Field Analysis were advised. A proper OPD, IPD, and OT documentation is done and the data in this study is collected from the above mentioned documents with required permission from the college authority.

\section{Observation and Results}

Total number of patients attended in the opd over a period of 12 months are 108628 out of which $56281(51.81 \%)$ are males and 52347(48.19\%) are females. 23181(21.34\%) patients attended the opd for follow up out of which 12096 are males and 11085 are females.

Table 1: Sex distribution

\begin{tabular}{|l|c|c|c|}
\hline \multicolumn{1}{|c|}{ Sex } & New & Follow up & Total \\
\hline Male & $44185(40.67 \%)$ & $12096(11.14 \%)$ & $56281(51.81 \%)$ \\
\hline Female & $41262(37.98 \%)$ & $11085(10.21 \%)$ & $52347(48.19 \%)$ \\
\hline
\end{tabular}

Table 2: Age distribution

\begin{tabular}{|c|c|c|c|}
\hline Age in years & Number of males & Number of females & Total and percentage \\
\hline Below 5 years & 9154 & 7241 & $163959(15.09 \%)$ \\
\hline $5-20$ years & 7438 & 9788 & $17226(15.86 \%)$ \\
\hline $21-35$ years & 6177 & 6521 & $12698(11.69 \%)$ \\
\hline $36-50$ years & 12651 & 10214 & $22865(21.05 \%)$ \\
\hline 51-65 years & 13009 & 11433 & $24442(22.50 \%)$ \\
\hline Above 65 years & 7852 & 7150 & $15002(13.81 \%)$ \\
\hline Total and percentage & $56281(51.81 \%)$ & $52347(48.19 \%)$ & $108628(100 \%)$ \\
\hline
\end{tabular}

Distribution of patients as per different category

49577(45.64\%) patients suffered from refractive errors 
Table 3: Distribution of refractive errors

\begin{tabular}{|l|c|c|c|}
\hline \multicolumn{1}{|c|}{ Refractive error } & Male & Female & Total \\
\hline Myopia & $7321(14.77 \%)$ & $5149(10.38 \%)$ & $12470(25.15 \%)$ \\
\hline Hypremetropia & $4506(9.08 \%)$ & $3500(7.05 \%)$ & $8006(16.13 \%)$ \\
\hline Astigmatism & $5997(12.1 \%)$ & $5231(10.55 \%)$ & $11228(22.65 \%)$ \\
\hline Presbyopia & $9691(19.55 \%)$ & $8182(16.50 \%)$ & $17873(36.05 \%)$ \\
\hline
\end{tabular}

24844(22.87\%) patients were having some general ophthalmolgy diseases

Table 4: Distribution of general ocular conditions

\begin{tabular}{|l|c|c|c|}
\hline \multicolumn{1}{|c|}{ Disease } & Male & Female & Total \\
\hline Conjunctivitis & $7477(30.1 \%)$ & $6543(26.33 \%)$ & $14020(56.43 \%)$ \\
\hline Keratitis & $753(3.03 \%)$ & $567(2.28 \%)$ & $1320(5.31 \%)$ \\
\hline Corneal ulcer & $598(2.40 \%)$ & $411(1.65 \%)$ & $1009(4.05 \%)$ \\
\hline Uveitis & $477(1.91 \%)$ & $691(2.78 \%)$ & $1168(4.69 \%)$ \\
\hline Hordeolum & $113(0.45 \%)$ & $197(0.79 \%)$ & $310(1.24 \%)$ \\
\hline Blepharitis & $216(0.87 \%)$ & $311(1.25 \%)$ & $527(2.12 \%)$ \\
\hline Other disorders & $3190(12.84 \%)$ & $3300(13.28 \%)$ & $6490(26.12 \%)$ \\
\hline
\end{tabular}

$17037(15.68 \%)$ patients were screened with cataract

$4554(4.19 \%)$ patients were diagnosed with retinal disorders

Table 5: Distribution of retinal disorders

\begin{tabular}{|l|c|c|c|}
\hline \multicolumn{1}{|c|}{ Retinal disorders } & Male & Female & Total \\
\hline Diabetic retinopathy & $503(11.05 \%)$ & $417(9.16 \%)$ & $920(20.21 \%)$ \\
\hline Retinal vein occlusion & $198(4.35 \%)$ & $179(3.93 \%)$ & $377(8.285)$ \\
\hline Macular edema & $190(4.17 \%)$ & $151(3.31 \%)$ & $341(7.48 \%)$ \\
\hline Retinal detachment & $234(5.14 \%)$ & $173(3.8 \%)$ & $407(8.94 \%)$ \\
\hline Armd and maculopathies & $575(12.62 \%)$ & $311(6.83 \%)$ & $886(19.45 \%)$ \\
\hline Others & $1016(22.31 \%)$ & $607(13.32 \%)$ & $1623(35.63 \%)$ \\
\hline
\end{tabular}

$6831(6.29 \%)$ patients were diagnosed as cases of glaucoma

$1519(1.40 \%)$ patients were treated for paediatric and neuro ophthalmology disorders

$2489(2.29 \%)$ patients were having oculoplasty related disorders

$1005(0.92 \%)$ patients were referred from other departments

$772(0.71 \%)$ patients were screened for ROP

\section{Distribution of admitted/operated patients}

$5769(5.31 \%)$ patients were admitted for cataract surgery.

$585(0.54 \%)$ patients were admitted for oculoplasty.

$534(0.49 \%)$ patients were admitted for accidental cases or emergency.

$211(0.19 \%)$ cases were admitted for general ophthalmology evaluation and management.

96(0.09\%) patients were admitted for paediatric and neuro ophthalmology intervention.

$77(0.07 \%)$ patients were admitted for glaucoma.

\section{Discussion}

Tis study shows a marginal male preponderance. This is in correlation to other studies as females in rural areas are often neglected and less educated about ocular health. ${ }^{3}$ More adults (>35 years) had eye diseases than children and younger patients. This trend was observed in other studies conducted by Lakho et $\mathrm{al}^{4}$ and Ajaiyeoba A.I et al. ${ }^{5}$ This trend is noted probably due to inability of children to express and lack of eye health awareness among parents. ${ }^{6}$ Thus it results in late presentation to ophthalmologists. This study area has dry dusty and hot climate thus allergic conjunctivitis, pterygium, dry eyes are more common. This is in correlation with studies conducted in other similar environment. $^{7-9}$

Uncorrected refractive errors and presbyopia are one of the most common cause of ocular morbidity and had impact on quality of life and leads to poor educational and socioeconomic outcomes. ${ }^{10,11}$ In our study presbyopia is most common ocular condition followed closely by myopia and hypermetropia. This is in correlation with studies conducted by Balarabe et al. ${ }^{11}$

In this study cataract was the second most common (15.68\%) cause of ocular morbidity. cataract was most common among people $>55$ years of age. This is in correlation with studies conducted by Puri D S et al, ${ }^{12}$ Sehgal RK et al,${ }^{13}$ Kanodia $\mathrm{P},{ }^{14} \mathrm{Haq}$ I et a ${ }^{15}$ but only $5.31 \%$ patients were operated for cataract. This may be due to some patients might have undergone cataract surgery at other places, or may be some patients neglected the condition and may not have turned up for cataract surgery. This data shows less orientation and awareness among people about ocular health.

Among retinal diseases, diabetic retinopathy and maculopathies were the leading causes of ocular morbidity 
in retina clinic which were managed either conservatively or by injecting anti VEGF or laser retinopexy procedures. This is in correlation with Onakpoya $\mathrm{O} \mathrm{H}$ et $\mathrm{al}^{16}$ and Reddy $\mathrm{S}$ et al. ${ }^{17}$ The cases which needed vitreo retina surgery (Retinal Detachment, Vitreous Hemorrhage, Macular Hole) were referred to regional institute of Kolkata for further management.

Among oculoplasty cases most of the cases operated were for chronic dacryocystitis either by dacryocystectomy or dacryocystorhinostomy depending on indications. Ectropion and entropion cases came as second most common.

In glaucoma clinic most of the patients were managed by medications. The patients not responding to medications were treated either by laser iridotomy or trabeculoplasty.

In paediatric and neuro ophthalmology clinic most of the patients were of ocular movement and alignment disorders. Cases of squints were treated with resection and recession of recti muscles after thorough evaluation to rule out chances of post operative diplopia. Congenital cataract were operated under general anaesthesia by phacoemulsification.

\section{Conclusion}

The pattern of diseases observed in this study are similar to studies from other part of the developing world this study helps in understanding the epidemiology of various ocular diseases and thus helping in proper planning and management of a hospital so that proper programmes can be put in place to minimise the burden of ocular morbidity.

\section{Source of funding}

None.

\section{Conflict of interest}

None.

\section{References}

1. WHO. Global data on visual impairments. (2010). http://www.who.int/blindness/GLOBALDATAFINALforweb. pdf. [Last accessed on March 21, 2016]

2. Friek KD, Foster A. The magnitude and costs of global blindness: An increasing problem that can be alleviated. Am J Ophthalmol 2003;135(4):471-6.

3. Kawuma M. Eye diseases and blindness in Adjumani refugee settlement camps, Uganda. East Afr Med J 2000;77:580-2.

4. Lakho, K.A. and Mohamed Ali, A.B. (2015) Pattern of Eye Diseases at Tertiary Eye Hospital in Sudan (Makah Eye Hospital, Khartoum). Albasar. Int J Ophthalmol 2015;3:158. https://doi.org/10.4103/1858-6538.169304

5. Ajaiyeoba A.I. Prevalence and Causes of Eye Diseases amongst Students in South-Western Nigeria. Ann Afr Med, 2006;5:197-203.

6. Parmar A, Kartha G, Baria M. A study on the Prevalence of Ocular Morbidities Amongst School Children (10-16 years) of Surendranager District. Int J Res Med 2014;3(3):90-4.

7. Olukorde OA, Oluymka JS. Pattern of eye diseases in air force hospital in Nigeria. Pak J Ophthalmol 2012;28:144-8.

8. Murad MA, Alam MS, Miah AKMA, Akter MS, Kabir MH. Pattern of eye diseases in a tertiary hospital in a suburban area: A retrospective study. Orion Med J 2007;28:492-4.
9. Sarita T, Sachin D. A pattern of ocular morbidity in patients attending anophthalmic clinic in a rural part of western Nepal. J Nobel Med Coll 2012;2:27-30.

10. Dandona L, Dandona R, Naduvilath TJ, McCarty CA, Srinivas $\mathrm{M}$, Mandal P, et al. Burden of moderate visual impairment in an urban population in southern India. Ophthalmol 1999;106:497-504.

11. Balarabe AH, Adamu S, Musa R. Presbyopia among health workers in a tertiary hospital in north western Nigeria. SubSaharan Afr J Med 2015;2:10-3.

12. Puri DS. Pattern and Distribution of Ocular Morbidity in Patients Visiting the Field Practice Area of Tertiary Care Hospital of North India. J Biomed Pharml Res 2013;2(2):42-6.

13. Sehgal RK, Garg R, Anand S, Dhot PS, Singhal P. A study of the morbidity profile of geriatric patients in rural areas of Ghaziabad, Uttar Pradesh. Int J Med Sci Public Health 2016;5(2):176-80.

14. Kanodia P, Mobin M, Malhotra R, Akram S M. The Pattern of Ocular Morbidity in a Tertiary Care Hospital in North India-A Hospital Based Cross-Sectional Study. JMSCR 2017;5(11):29889-92.

15. Haq I. Prevalence of common ocular morbidities in adult population of Aligarh. Indian J Community Med: official publication of Indian Associ Prev Soc Med 2009;34(3):195201.

16. Onakpoya OH, Olateju SO, Ajayi IA. Retinal diseases in a tertiary hospital: The need for establishment of a vitreo-retinal care unit. J Natl Med Assoc 2008;100:1286-9.

17. Reddy S, Tajunisah I, Low K, Karmila A. Prevalence of eye diseases and visual impairment in urban population-A study from university of Malaya Medical Centre. Malays Fam Physician 2008;3:25-8.

How to cite this article: Agrawalla RK, Mondal A. Spectrum of medical and surgical patients in ophthalmology department of a Government medical college in Bankura district of West Bengal - a retrospective review. J Community Health Manag 2019;6(3):94-7. 